\title{
UTILIZANDO A EXPERIMENTAÇÃO PARA TRABALHAR OS ESTADOS FÍSICOS E A TRANSFORMAÇÃO DA MATÉRIA: UMA REVISÃO DE LITERATURA
}

\section{HENRIQUE JOSÉ DE OLIVEIRA'}

Instituto Federal de Educação, Ciência e Tecnologia do Piauí (IFPI)

E-mail: henrique.bio22@gmail.com

\section{LEONARDO MOURA DOS SANTOS SOARES"}

Instituto Federal de Educação, Ciência e Tecnologia do Piauí (IFPI)

E-mail: leonardomss65@hotmail.com

RESUMO:

Muito se tem discutido a respeito da importância das aulas de Ciências Naturais, bem como a importância de que o professor utilize metodologias além do ensino tradicional. Analisamos como os professores de ciências da educação básica utilizam a experimentação para trabalhar os estados físicos e a transformação da matéria em suas aulas. Para a realização deste trabalho utilizamos a pesquisa do tipo bibliográfica e qualitativa, possibilitando conhecer como a experimentação está sendo utilizada na sala de aula durante as aulas de ciências. Após a análise dos trabalhos, o que ficou mais evidente foi que a experimentação pode e deve ser utilizada na sala de aula, pois tanto alunos quanto professores destacaram a sua importância. Portanto, enfatizamos a relevância das aulas práticas em Ciências Naturais, pois elas contribuem para um processo de ensino e aprendizagem mais dinâmicos e significativo.

\section{PALAVRAS-CHAVE:}

Ensino de ciências, Experimentação em ciências, Aulas práticas.

USING EXPERIMENTATION TO WORK ON PHYSICAL STATES AND THE TRANSFORMATION OF MATTER: A LITERATURE REVIEW

\section{ABSTRACT:}

Much has been discussed about the importance of Natural Science classes, as well as the importance of the teacher using methodologies beyond traditional teaching. We analyze how basic education teachers use experimentation to work on physical states and the transformation of matter in their classes. In order to carry out this work, we used bibliographical and qualitative 
research, making it possible to know how experimentation is being used in the classroom during science classes. After analyzing the works, what became more evident was that experimentation can and should be used in the classroom, as both students and teachers highlighted its importance. Therefore, we emphasize the relevance of practical classes in Natural Sciences, as they contribute to a more dynamic and meaningful teaching and learning process.

\section{KEYWORDS:}

Science teaching, Science experimentation, Practical classes.

\section{INTRODUÇÃO}

Muito se tem discutido a respeito da importância das aulas de Ciências Naturais, bem como a recomendação de que o professor não concentre sua didática e metodologia apenas ao ensino tradicional, promovendo assim aulas mais atrativas e dinâmicas para seus alunos. Apesar disso, Santos (2007) destaca que a maneira como o ensino de Ciências no ensino fundamental tem sido trabalhada, na maioria das vezes, é voltado para uma maneira tradicional de abordagem, onde a mesma baseia-se na memorização de conceitos, termos científicos e sistemas classificatórios; de modo que os estudantes apesar de aprenderem tais termos, não se tornam capazes de contextualizar o significado de sua linguagem e utilizar esse conhecimento no seu cotidiano.

Belian, Lima e Freitas Filho (2017) enfatizam que, de fato, no ensino de Ciências, principalmente quando o professor introduz a Química, é necessário que haja uma diversidade de metodologias e que estas sejam condizentes com os materiais didáticos e pedagógicos que estejam à disposição do professor em sala de aula. Relatos da literatura demonstram o interesse dos estudantes por atividades experimentais, contribuindo para o ensino de ciências em geral. Contudo, essas 
propostas de aulas mais dinâmicas ainda são pouco utilizadas nas instituições de ensino da educação básica, principalmente nas escolas públicas.

Para Silva (2016), uma maneira de contextualizar os conteúdos em sala de aula é a utilização de conceitos práticos de química que podem ser observados no cotidiano do aluno, fazendo com que eles se sintam motivados a buscar as explicações para tais fenômenos e produzam seus próprios conceitos.

Uma das principais características relacionadas ao ensino de Química, segundo Merçon (2003) tanto no ensino fundamental quanto no ensino médio, é a falta de interesse dos alunos em estudar esta disciplina. Essa falta de interesse pode estar diretamente relacionada à metodologia tradicional usada pelo professor, onde muitas vezes esse profissional não procura fazer uma relação desta ciência com o contexto social do educando, principalmente no que diz respeito a conceitos relacionados a transformações de estados físicos da matéria.

Trabalhar os estados físicos da matéria e sua transformação, muitas vezes, torna-se difícil, pois os alunos não conseguem contextualizar as informações. Muitos professores alegam não ter laboratório para inserir práticas experimentais para aperfeiçoar o aprendizado do aluno. O fato é que alguns experimentos não requerem uma estrutura laboratorial, o que possibilita questionar se o uso de experimentos em sala de aula melhora o aprendizado acerca dos estados físicos da matéria bem como suas transformações.

Para Zechim (2008), as atividades experimentais podem trazer uma associação entre teoria e prática, fazendo assim com que o distanciamento entre o aprendido em sala de aula com o reproduzido no dia a dia seja reduzido, principalmente 
quando os professores estiverem trabalhando conceitos de química nas aulas de ciências, fato que ocorre geralmente com mais frequência nas turmas de 6o e 9o anos do ensino fundamental.

No processo de ensino e aprendizagem, na visão de Zechim (2008), o professor ao utilizar as atividades experimentais como estratégia de ensino faz a mediação na construção do saber científico, atuando como professor mediador/facilitador. Para Vygotsky (1994, p. 75), a aprendizagem se dá por meio das interações sociais, tanto entre indivíduos como entre indivíduos e o meio; onde o indivíduo aprende por meio desta interação. Além da importância da socialização no processo de construção do conhecimento, a afetividade também tem um importante papel na construção do próprio sujeito e em suas ações. Desse modo, a relação professor-aluno deve conter este fator interativo e afetivo.

O conhecimento de procedimentos é ainda considerado como aspecto fundamental do ensino experimental de ciências, em detrimento à reflexividade e ao conhecimento de conceitos; prevalece essa visão simplista de que a experimentação contribui automaticamente para a melhoria das aulas de ciências e para a aquisição do conhecimento científico por parte dos alunos (SILVA e ZANON, 2000, p. 126). Porém, é importante que os professores considerem que os alunos devem entender todo o processo da experimentação e não apenas o seu resultado.

Em face destes pressupostos, nosso objetivo foi analisar como os professores de ciências da educação básica utilizam a experimentação para trabalhar os estados físicos e a transformação da matéria em suas aulas. Além disso, visamos enfatizar a importância das aulas práticas no ensino de Ciências Naturais.

\section{FUNDAMENTAÇÃO TEÓRICA}

\section{(c) (1) () $९$}


Para Reginaldo et al. (2012), o uso das atividades experimentais é uma prática pedagógica que tem ganhado bastante espaço no âmbito educacional, em razão da sua relevância para efetivação do processo de ensino-aprendizagem. É preciso refletir sobre a sua utilização em sala de aula, no que tange ao professor demonstrar o vínculo entre teoria e prática, que é a finalidade da investigação científica por experimentação.

As atividades experimentais foram inseridas nas instituições de ensino em detrimento da influência de trabalhos realizados nas universidades, cujo objetivo é de melhorar a aprendizagem do conhecimento científico por meio da prática do que foi aprendido, o que a tornou indispensável na docência atualmente. (GALIAZZI et al., 2001).

Reginaldo et al. (2012) defendem a importância da experimentação durante as aulas de ciências, visto que esta desperta tanto o interesse dos educandos quanto dinamizam o fazer pedagógico do docente da educação básica, principalmente nas séries finais do ensino fundamental.

As aulas experimentais podem ser utilizadas com diferentes objetivos, fornecendo variadas e importantes contribuições no processo de ensino e aprendizagem de ciências, desde estratégias que focalizam a simples ilustração ou verificação de leis e teorias, até aquelas que estimulam a criatividade dos alunos, dando condições para refletirem e reverem suas ideias a respeito dos fenômenos científicos (OLIVEIRA, 2010, p. 28).

Não é apenas a disciplina de Ciências que requer a utilização de aulas práticas experimentais, porém como esta disciplina é, de certo modo, muito visual, por meio da experimentação, fica mais fácil e prático os alunos aprenderem o conteúdo, tendo assim um maior proveito dele.

\section{(c) (1) ()}


Para Vieira et al. (2014), a química é articulada com a experimentação, visto que ambas necessitam da visão para estimulação da aprendizagem nas aulas laboratoriais, onde se destaca que o sentido supramencionado é indispensável na efetivação e significação da experimentação para a ciência de forma geral, mas principalmente nas ciências naturais.

Para Merçon (2003, p. 4), a utilização de experimentos em aulas práticas demonstrou ser uma abordagem possível no ensino de Química, pois as aulas práticas proporcionam motivação aos alunos. Além disso, o autor destacou que o experimento favorece a construção do conhecimento, estimulando o caráter investigativo e a contextualização por parte dos discentes na escola.

Na visão de Fonseca e Soares (2017), é de grande relevância inserir o aluno em aulas práticas, para que ele possa potencializar sua capacidade científica, bem como conseguir fazer uma relação entre teoria e prática. Os professores necessitam ter a visão de que a formação científica do aluno, para que o mesmo consiga formular e testar hipóteses, deve começar logo na educação básica, de preferência no ensino fundamental.

Na visão de Silva (2016), maioria dos professores tem o conceito de que aulas experimentais transformam o aprendizado do aluno, porém aulas desse cunho ainda não fazem parte da realidade de todas as escolas brasileiras, as justificativas são as mais variadas, girando em torno da falta de recursos didáticos e financeiros e laboratórios bem equipados. Contudo é sabido que essas aulas podem ser realizadas com materiais de baixo custo e até mesmo adaptados e/ou reciclados e/ou reutilizados pelos professores. 
Gonçalves (2005) aborda que muitos trabalhos destacam o que foi exposto no comentário supracitado, onde maioria das vezes a não realização de aulas práticas ou experimentais, se dá pelo fato da não existência de laboratório nas escolas, ou mesmo que a escola possua este espaço, faltam recursos para a manutenção dele. Isso muitas vezes ocorre pelo fato de que muitos professores, quando pensam em realizar aulas experimentais, imaginam logo que estas devam requerer materiais de laboratórios.

Porém, Silva (2016) destaca ainda que essa problemática relacionada à falta de recurso não influencia e nem justifica, pois existem diversas maneiras de se trabalhar a experimentação na própria sala de aula e utilizando materiais acessíveis e de baixo custo. Atualmente os professores podem também encontrar diversos manuais com aulas práticas fáceis de serem realizadas. Muitos livros didáticos, inclusive, trazem aos finais de capítulos as experiências práticas relacionadas àquela unidade de ensino.

Compreender a função do processo de ensino, bem como o uso da experimentação em Ciências, não pode ser atrelado apenas à concepção de Ciência experimental de forma impositiva, mas desafiador para motivar os alunos a construir um conhecimento contextualizado e problematizado no ensino de Ciências (KORNOWSKI et al., 2016, p. 538).

Muitas propostas nas aulas de Química e Ciências ainda deixam de considerar a importância da experimentação atrelada ao ensino, por considerar que esta necessita de observações naturais. Por isso cabe ao professor, criar estratégias metodológicas que possam suprir essa necessidade escolar (GIORDAN, 1999). Daí a importância de estabelecer relações entre o cotidiano do aluno e o conhecimento científico, que se consegue fazer uma contextualização, e fazer com que o aluno

\section{(c) (1) (3)}


traga conhecimentos prévios para a sala de aula, dinamizando assim o ensino e fazer pedagógico (GUADIX; TORRES; LISO, 2002).

Em seu trabalho, Silva (2016) infere ainda que a experimentação pode exercer no Ensino de Química e Ciências um papel fundamental, visto que os alunos ao participarem das aulas, elaborando e testando hipóteses, deixam de ser receptores e passam a ser construtores do conhecimento de forma ativa. Portanto, a experimentação se mostra como uma forma de melhorar a compreensão dos alunos sobre os fenômenos, que muitas vezes, se explicados apenas em uma aula de aula convencional, talvez não atinja o mesmo objetivo.

Segundo Fonseca e Soares (2017), o fato de o experimento ser realizado não garante sucesso naquela aula, pois o professor deve inserir o aluno de modo que ele entenda a sua participação e não apenas que ele observe o experimento de uma forma passiva, o aluno tem que se sentir fazendo parte da aula e fazer interações e indagações juntamente com os colegas de classe.

\section{PERCURSO METODOLÓGICO}

Esta pesquisa teve caráter exploratório. De acordo com Gil (2008) pesquisas bibliográficas proporcionam uma maior familiaridade com o problema, podendo envolver levantamento bibliográfico e entrevistas com pessoas experientes no tema pesquisado. Geralmente, assume a forma de pesquisa bibliográfica ou estudo de caso. Para a realização deste trabalho, utilizamos a pesquisa do tipo bibliográfica e qualitativa, possibilitando conhecer, através de materiais adquiridos na internet, como a experimentação está sendo utilizada na sala de aula durante as aulas de Ciências.

\section{(c) (1) () $९$}


Bervian, Cervo e Silva (2007, p. 60) descrevem que a pesquisa bibliográfica a partir de referenciais teóricos propõe-se a conhecer e analisar as relevâncias culturais e científicas sobre determinado tema ou problemática. Assim, a pesquisa bibliográfica é o ponto de partida de qualquer pesquisa científica, pois, permite ao pesquisador a partir do contato com materiais elaborados e publicados, saber em que estado se encontra o problema investigado.

De acordo com o exposto por Fonseca (2002, p. 32), a pesquisa bibliográfica é feita a partir do levantamento de referências teóricas já analisadas, e publicadas por meios escritos e eletrônicos, como livros, artigos científicos e páginas de web sites. Qualquer trabalho científico inicia-se com uma pesquisa bibliográfica, que permite ao pesquisador conhecer o que já se estudou sobre o assunto.

Existem, porém, pesquisas científicas que se baseiam unicamente na pesquisa bibliográfica, procurando referências teóricas publicadas com o objetivo de recolher informações ou conhecimentos prévios sobre o problema a respeito do qual se procura a resposta (FONSECA, 2002, p. 33).

Goldenberg (1997, p. 34) aborda que a pesquisa qualitativa não se preocupa com representatividade numérica, mas, sim, com o aprofundamento da compreensão de um grupo social, de uma organização ou de um tema.

\section{LEVANTAMENTO DE DADOS E ANÁLISE DOS RESULTADOS}

Para o levantamento das referências e da bibliografia, utilizamos os seguintes descritores: experimentação em ciências, aulas práticas no estudo da matéria, estados físicos da matéria, uso da experimentação na escola; de forma isolada ou combinados. Utilizamos estes descritores em sites como Google acadêmico e Scielo. 
Como critérios de inclusão da pesquisa eletrônica, os parâmetros utilizados foram: possuir texto completo disponível, ser publicado em português em revista indexada ou anais de congressos (artigos), tratar do objeto de estudo desta revisão de literatura e estar disponível gratuitamente na internet. Os trabalhos analisados tiveram que ser datados pelo menos nos últimos 10 anos. Após os arquivos como: livros, capítulos de livros, artigos, monografias, dissertações e teses, serem encontrados e lidos, fizemos o trabalho de revisão.

Vários autores foram consultados e parte de suas obras foram citadas, a fim de que pudesse ser estabelecida a fundamentação teórica, a partir da qual buscamos atender ao objetivo principal do estudo por meio da discussão dos resultados obtidos. Para análise e discussão dos resultados utilizamos 12 trabalhos, sendo: 08 artigos científicos, 02 dissertações de mestrado e 02 trabalhos de conclusão de curso de graduação e especialização.

Realizamos a análise dos resultados a partir de fichamentos dos trabalhos selecionados, visamos identificar similaridades entre os mesmos, em relação a como a experimentação é utilizada em sala de aula pelos professores de ciências naturais.

\section{RESULTADOS E DISCUSSÃO}

Após a análise dos trabalhos selecionados, optamos por elaborar um quadro demonstrativo para tornar mais didática a visualização deles. O quadro pode ser conferido abaixo (Quadro 1).

Quadro 1. Trabalhos utilizados na revisão bibliográfica. Fonte: Autores.

\begin{tabular}{|l|l|l|}
\hline Título & Ano de trabalho & Ano \\
\hline
\end{tabular}

(1) (1) 9

Licença Creative Commons - Atribuiçăo-NăoComercial-Sem Derivaçōes 4.0 Internacional. 


\begin{tabular}{|c|c|c|}
\hline & & publicação/conclusão \\
\hline $\begin{array}{l}\text { Uma experimentação sobre estados físicos da } \\
\text { matéria: contribuições da inserção à docência }\end{array}$ & Artigo científico & 2016 \\
\hline $\begin{array}{l}\text { Mudanças de estados físicos da matéria: fusão, } \\
\text { Vaporização, condensação, solidificação } \\
\text { Sublimação, para deficientes visuais }\end{array}$ & Artigo científico & 2014 \\
\hline $\begin{array}{l}\text { A experimentação na identificação das } \\
\text { transformações físicas e químicas }\end{array}$ & Artigo científico & 2013 \\
\hline $\begin{array}{l}\text { A experimentação no ensino de ciências: relaçã } \\
\text { Teoria e prática }\end{array}$ & Artigo científico & 2017 \\
\hline $\begin{array}{l}\text { Experimentação como ferramenta pedagógica } \\
\text { para o ensino de Ciências }\end{array}$ & Artigo científico & 2016 \\
\hline O ensino de ciências e a experimentação & Artigo científico & 2012 \\
\hline $\begin{array}{l}\text { A atividade experimental no ensino de ciências } \\
\text { naturais: contribuições e contrapontos }\end{array}$ & Artigo científico & 2018 \\
\hline $\begin{array}{l}\text { Atividades práticas e o ensino-aprendizagem de } \\
\text { ciência(s): mitos, tendências e distorções }\end{array}$ & Artigo científico & 2014 \\
\hline $\begin{array}{l}\text { Experimentação e simulação computacional no } \\
\text { ensino de Estados físicos da matéria e transições } \\
\text { de fase na educação Básica }\end{array}$ & Dissertação de mestrado & 2016 \\
\hline $\begin{array}{l}\text { A experimentação no Ensino de Ciências } \\
\text { possibilidades e limites na busca de uma } \\
\text { Aprendizagem Significativa }\end{array}$ & Dissertação de mestrado & 2010 \\
\hline $\begin{array}{l}\text { A experimentação no ensino de ciências } \\
\text { importância das aulas práticas no processo de }\end{array}$ & Monografia de & 2013 \\
\hline
\end{tabular}




\begin{tabular}{|l|c|c|}
\hline ensino aprendizagem & especialização & \\
\hline A importância da experimentação no ensino de & Monografia de graduação & 2016 \\
química e ciências & & \\
\hline
\end{tabular}

Abaixo pode-se observar os resultados que os autores dos trabalhos acima citados obtiveram, além das discussões acerca da temática deste referido trabalho.

No trabalho de Kornowski et al. (2016) ficou evidente que bolsistas do PIBID ao longo das suas vivências vêm percebendo a relevância do uso de experimentos em sala de aula por parte do professor, de modo que possa ocorrer um aperfeiçoamento do aprendizado do aluno. Os autores perceberam também que houve um enriquecimento da atuação profissional dos bolsistas, pois ao se realizar uma aula prática juntamente com a professora titular da turma, adquiriu-se conhecimento mútuo.

O que pudemos perceber foi que ao mesmo tempo em que futuros docentes e bolsistas de iniciação à docência aprendem com os professores titulares das turmas trabalhadas, os alunos dessas turmas também aprendem com os bolsistas e professores, desta forma a experimentação traz uma contribuição no processo de ensino-aprendizagem e na formação docente inicial e continuada.

Vieira et al. (2014) realizaram um trabalho abordando a experimentação com alunos deficientes visuais e eles destacaram que a realização de atividades experimentais no Ensino de Química traz grandes contribuições para o processo de ensino-aprendizagem desta disciplina. Na pesquisa realizada, notou-se que os 
materiais didáticos e a experimentação são muito relevantes para proporcionar uma aprendizagem significativa aos alunos, independente das suas limitações físicas.

Quando refletimos sobre ciências naturais e no quão esta área do conhecimento é extremamente visual e requer experimentação, muitas vezes não lembramos que existem alunos que são deficientes visuais, deste modo cabe ao professor elaborar materiais didáticos que possam estimular também o tato e o olfato e não apenas a visão, para que a aprendizagem não seja excludente.

Ao fazer uma análise conjunta dos trabalhos de Kornowski et al. (2016) e Vieira et al. (2014) o que se pode observar é que a experimentação foi colocada como ponto de partida, porém os trabalhos abordaram bem mais que isso. Enquanto o primeiro enfatizou a questão da formação docente, o segundo destacou a educação inclusiva. Deste modo, notamos que fazer experimentos em sala de aula é bem mais do que fazer com que a teoria seja aliada à prática.

Souza et al. (2013) destacaram que infelizmente há uma escassez de recursos laboratoriais, o que de certo modo os professores usam como justificativa para a não realização de aulas mais práticas. Mas os autores puderam observar em seu trabalho que é possível trabalhar a química, com recursos simples, de baixo custo e de fácil aquisição para uma aula mais dinâmica e prazerosa, mostrando ao aluno a química do cotidiano.

Como pôde ser confirmado pelos autores acima, a questão da experimentação não está ligada necessariamente ao fato de a escola ter ou não um laboratório, existem diversas maneiras de se fazer experimentos em sala de aula e de maneira significativa, tanto para o aluno quanto para o professor. 
O projeto de Experimentação no Ensino de Ciências: Relação Teoria e Prática, realizado por Fonseca e Soares (2017), com os estudantes do 9으 Ano de uma escola paranaense, durante o primeiro semestre de 2017, contribuiu de forma eficiente, incentivadora, prazerosa e positiva, no que diz respeito ao aprendizado dos alunos. Segundo os autores, houve a participação de todos que estavam em seus grupos de trabalho, tanto no que diz respeito ao empenho na investigação e na contextualização e apresentação dos resultados obtidos.

Geralmente, a investigação científica e a experimentação são realizadas nas escolas por meio de projetos ou feiras, o que de certo modo é relevante, porém um grande desafio atual é que o professor consiga inserir tais contextos em sua prática docente diária, para que dessa forma o aluno não veja a experimentação como algo diferente, mas sim como algo necessário, natural e complementar à teoria.

No trabalho de Taha et al. (2016) os autores ao apresentarem sua pesquisa, a intencionalidade dos mesmos foi perceber a contribuição da experimentação para a qualidade do ensino de Ciências. No entanto, a partir da pesquisa, eles acreditaram que a experimentação é capaz de fazer com que os alunos tenham motivação em sala de aula, mas que para isso o professor deve ser capaz de ouvir dos alunos as suas necessidades e anseios.

Os autores acima mencionaram que a experimentação é de suma importância, pois pode ser realizada de muitas formas, mas todas elas têm algo em comum que é a problematização. É necessário que a experimentação quanto ao seu tipo, seja adequada à faixa etária e nível dos alunos, por isso há uma necessidade de o professor ouvi-los de forma a entender melhor seus anseios e dificuldades.

\section{(c) (1) (3)}


Reginaldo et al. (2012) realizaram uma entrevista com professores de ciências, onde a maioria tinha uma concepção contextual da experimentação, que é importante, pois significa que não estão pensando de modo fragmentado e tradicional e que não acreditam que reproduzir experimentos ou copiar práticas resolva os problemas do ensino de Ciências. Ou seja, é mais do que isso, é uma aproximação do mundo real (contexto, cotidiano e teoria), analisando os fenômenos, integrando e interagindo para produzir novos conceitos. É visível, então, que a maioria dos professores tem essa concepção da importância da experimentação nas aulas de ciências, mas por que muitos não a fazem? Cabe uma reflexão acerca disso, pois não adianta ficar só na teoria quando se sabe da importância da prática.

O trabalho de Catelan e Rinaldi (2018) aborda a ausência regular na realização de atividades experimentais em uma escola estadual do Mato Grosso. O estudo elenca que apesar das dificuldades é pertinente a análise sobre a importância de trabalhar essas propostas de investigação a fim de fomentar o processo de ensinoaprendizagem. Mesmo frente a essas dificuldades, se faz necessária uma reflexão sobre a importância de trabalhar com atividades experimentais no ensino. As contribuições acima reforçam o que já foi mencionado, de modo que o aluno quando se depara com atividades práticas, dinâmicas e diferenciadas, adquire um maior interesse pelas aulas e consequentemente pela ciência.

Tanto o trabalho de Fonseca e Soares (2017) quanto o de Catelan e Rinaldi (2018) foram realizados em escolas, tendo como foco os alunos, porém Reginaldo et al. (2012) focou em abordar os professores quanto a experimentação. Desta forma, o que podemos inferir aqui é que não apenas tratando-se de experimentação, mas qualquer outro tema nas aulas de ciências ou em outras disciplinas, o pesquisador 
pode escolher por trabalhar com professores ou alunos, colhendo assim os resultados com um olhar diferenciado.

Bassoli (2014) discutiu a questão da experimentação, fazendo uma análise dos aspectos epistemológicos e didáticos enfatizando, sobretudo as políticas públicas e os aspectos humanos, exemplificando que é preciso disciplina, respeito, cooperação e engajamento na sala de aula para que ocorra com êxito a aula experimental. A abordagem supracitada é relevante, pois vislumbra a preocupação tanto com a prática docente quanto com os conteúdos que devem ser ministrados, com a finalidade de frisar o real valor da educação, que é de transformar o sujeito de forma crítica e reflexiva. Infere-se assim, que as aulas mais atrativas têm um impacto maior na vida do aluno.

O trabalho de Brasil (2016) demonstrou que é possível aprender Química com o uso de simuladores, os quais são úteis na sala de aula, pois apresentam aos alunos inovação, que desperta interesse para além do ambiente comum de aprendizagem. Sendo assim, a tecnologia é eficiente na aprendizagem do aluno, visto que é uma estratégia metodológica que proporciona autonomia e dinamiza o ensino.

Aqui evidenciamos a experimentação de uma abordagem diferenciada, onde esta não faz uso de reagentes e nem de vidrarias, porém cabe ressaltar o que anteriormente foi dito, que a experimentação possui formas variadas de ser abordada, desde a utilização de materiais de baixo custo a utilização de materiais mais complexos, de modo que não importa o aspecto, mas a eficácia é garantida, pois os alunos se doam mais ao processo de ensino. 
Giani (2010) afirmou em seu trabalho uma reflexão acerca das atividades experimentais que são desenvolvidas e viáveis para o Ensino de Ciências, as quais buscam contribuir para aquisição de conteúdo e interação entre alunos e professor. No projeto em questão, analisou-se a investigação planejada com algumas atividades práticas. A autora abordou a aprendizagem significativa na sua dissertação de mestrado. Essa aprendizagem é justamente o que muitos professores vêm tendo dificuldade em propor aos seus alunos, pois muitas vezes o aluno fica frente a um determinado conteúdo sem saber qual a aplicabilidade no seu cotidiano. Então fica claro aqui que a experimentação auxilia o aluno a entender o conteúdo de ciências como fazendo parte da vida dele, trazendo assim uma aprendizagem com significado social e científico.

Os resultados dos questionários respondidos por professores durante o trabalho de Souza (2013) demonstraram que há entendimento da necessidade de aliar as possibilidades que os recursos tecnológicos podem oferecer para melhorar a qualidade das aulas que são desenvolvidas, pois o uso de diferentes estratégias permite desenvolver, despertar o conhecimento dos educandos das mais diversas formas tornando o ato de aprender significativo e prazeroso.

Para Silva (2016) os processos de aprendizagem de conteúdos conceituais e procedimentais são estabelecidos por meio de atividades investigativas. Além disso, é unânime que esse tipo de atividade, independente do ambiente onde são realizadas, seja a sala de aula, laboratórios, ou qualquer outro espaço (formal ou informal), são significativamente distintas das atividades de demonstração e verificação, o que possibilita a promoção do papel proativo dos educandos no desenvolvimento das aulas. 
Podemos observar que de acordo com os trabalhos mencionados acima, tanto na visão do aluno quanto na visão do professor as aulas investigativas, sejam elas dentro ou fora da sala de aula, têm um papel muito importante no processo educativo, pois complementam a aula teórica ou algumas vezes pode até ser realizada em conjunto, ao tempo que é dada teoria é realizada a prática por meio da experimentação e investigação.

\section{CONSIDERAÇÕES FINAIS}

A problemática inicial do trabalho foi pautada em buscar saber como os professores de ciências utilizam a experimentação para trabalhar os estados físicos e a transformação da matéria em suas aulas; além disso notamos que, de acordo com a literatura, muitos professores alegam não ter laboratório para realização de experimentos durante as aulas. Durante a análise dos trabalhos utilizados nesta revisão bibliográfica ficou nítido que a experimentação não requer obrigatoriamente a utilização de equipamentos laboratoriais, pois ela pode ser realizada na própria sala de aula e com materiais de fácil acesso, basta que o professor faça um bom planejamento prévio.

Levantamos inicialmente o questionamento se o uso de experimentos em sala de aula melhora o aprendizado acerca dos estados físicos da matéria; foi observado então que com base no material já produzido e encontrado na internet, todos os autores mencionaram que sim, a experimentação contribui de forma positiva e significativa no processo de ensino-aprendizagem, não apenas tratando-se do conteúdo mencionado, mas de qualquer outro que seja. 
O que ficou mais evidente foi que a experimentação pode e deve ser utilizada na sala de aula, pois tanto alunos quanto professores destacaram a sua importância. Outra questão bem evidenciada foi a de que a utilização de experimentos não necessariamente é uma atividade que demanda tempo e dinheiro, pois é extremamente viável a sua realização por meio de materiais de baixo custo financeiro.

Portanto, o que podemos concluir é que o objetivo do trabalho foi alcançado. Além disso, enfatizamos a importância das aulas práticas em Ciências Naturais, de forma que os trabalhos analisados deixaram claro a sua contribuição positiva tanto para os alunos quanto para os professores e futuros docentes.

\section{REFERÊNCIAS}

BASSOLI, Fernanda. Atividades práticas e o ensino-aprendizagem de ciência(s): mitos, tendências e distorções. Revista Ciência \& Educação, Bauru, v. 20, n. 3, p. 579$593,2014$.

BELIAN, Mônica Freire; LIMA, Analice Almeida; FREITAS FILHO, João Rufino de. Ensinando química para séries iniciais do ensino fundamental: $O$ uso da experimentação e atividade lúdica como estratégias metodológicas. Experiências em Ensino de Ciências, V. 12, N. 4, 2017.

BERVIAN, Pedro A.; CERVO, Amado L.; SILVA, Roberto da. Metodologia Científica. 6. ed. São Paulo: Pearson Prentice Hall, 2007.

BRASIL. LITCHINA, Camila. Experimentação e simulação computacional no ensino de estados físicos da matéria e transições de fase na educação básica. Dissertação (Mestrado) - Universidade Federal do Pampa, Mestrado profissional em 
ensino

de

ciências,2016.Disponívelem:<http://bdtd.ibict.br/vufind/Record/UNIP_2d6c52ad51b f04a1ac69bafc0d2376cc>. Acesso em: 15 de maio de 2020.

CATELAN, Senilde Solange; RINALDI, Carlos. A atividade experimental no ensino de ciências naturais: contribuições e contrapontos. Experiências em Ensino de Ciências, V.13, N.1, 2018.

FONSECA, João José Saraiva da. Metodologia da pesquisa científica. Fortaleza: UEC, 2002. In: GIL, Antonio Carlos. Métodos e técnicas de pesquisa social. 5. Ed. São Paulo: Atlas, 1999.

FONSECA, Wander; SOARES, J. A. A experimentação no ensino de ciências: relação teoria e prática. Cadernos PDE, v.1, 2017.

GALIAZZI, Maria do Carmo. et al. Objetivos das Atividades Experimentais no Ensino Médio: A pesquisa coletiva como modo de formação de professores de ciências. Revista Ciência \& Educação, v.7, n.2, 2001.

GIANI, Kellen. A experimentação no Ensino de Ciências: possibilidades e limites na busca de uma Aprendizagem Significativa. Dissertação (Mestrado) - Universidade de Brasília, Mestrado em ensino de ciências, 2010. Disponível em: <https://repositorio.unb.br/handle/10482/9052>. Acesso em: 15 de maio de 2020.

GIL, Antonio Carlos. Como elaborar projetos de pesquisa. 4. Ed. São Paulo: Atlas, 2008.

GIORDAN, Marcelo. O Papel da Experimentação no Ensino de Ciências. Química Nova na Escola, Experimentação e ensino de ciências, 1999. Disponível em: 
<http://qnesc.sbq.org.br/online/qnesc10/pesquisa.pdf>. Acesso em: 21 de agosto de 2021.

GOLDENBERG, Mirian. A arte de pesquisar. Rio de Janeiro: Record, 1997.

GONÇALVES, Fábio Peres. O texto de experimentação na educação em química: discursos pedagógicos e epistemológicos. Tese (Doutorado) - Universidade Federal de Santa Catarina, Centro de Ciências da Educação. Programa de Pósgraduação em Educação Científica e Tecnológica, 2005.

KORNOWSKI, Jane. et al. Uma experimentação sobre estados físicos da matéria: contribuições da inserção à docência. CCNEXT - Revista de Extensão, Santa Maria v.3 - n.Ed. Especial XII EIE- Encontro sobre Investigação na Escola, 2016.

GUADIX, Ángeles Sánchez; TORRES, Esteban de Manuel; LISO, María Ruth Jiménez. Química cotidiana para la alfabetización científica: ¿realidad o utopía?. Educación Química, v.13, n.4, 259- 266, 2002.

MERÇON, Fábio. A experimentação no ensino de química. Anais do IV encontro nacional de pesquisa em educação em ciências. 2003. Disponível em: <http://www.abrapecnet.org.br/enpec/iv-enpec/Arquivos/Painel/PNL016.pdf>. Acesso em: 14 de julho de 2019.

OLIVEIRA, Jane Raquel Silva de. A Perspectiva Sócio-histórica de Vygotsky e suas relações com a Prática da Experimentação no Ensino de Química. Alexandria Revista de Educação em Ciências e Tecnologia, 3(3) 25-45, 2010.

REGINALDO, Carla Camargo. et al. O ensino de ciências e a experimentação. Anais do Seminário de pesquisa em educação da região Sul, 2012. Disponível em:

\section{(c) (1) (3) 9}


<http://www.ucs.br/etc/conferencias/index.php/anpedsul/9anpedsul/paper/viewFil e/2782/286>. Acesso em: 15 de maio de 2020.

SANTOS, Wildson Luiz Pereira dos. Educação científica na perspectiva de letramento como prática social: funções, princípios e desafios. Revista Brasileira de Educação, São Paulo, 12(36) 474-550, 2007.

SILVA, Lenice Heloísa de Arruda; ZANON, Lenir Basso. A experimentação no ensino de ciências. p.120-153. In: Schnetzler, Roseli Pacheco. (org.). Ensino de Ciências: fundamentos e abordagens. São Paulo, UNIMEC/CAPES, Editora Itda, 2000.

SILVA, Vinícius Gomes da. A importância da experimentação no ensino de química e ciências. Monografia (Graduação). UNESP. BAURU, 2016. Disponível em: <https://repositorio.unesp.br/bitstream/handle/11449/136634/000860513.pdf>. Acesso em: 14 de julho de 2019.

SOUZA, Alessandra Cardosina de. A experimentação no ensino de ciências: importância das aulas práticas no processo de ensino aprendizagem. Monografia (Especialização) - Universidade Tecnológica Federal do Paraná, Especialização em Educação: Métodos e Técnicas de Ensino, 2013. Disponível em: <http://repositorio.roca.utfpr.edu.br/jspui/bitstream/1/4718/1/MD_EDUMTE_II20 12_20.pdf. Acesso em: 15 de maio de 2020>.

SOUZA, Larissa Oliveira de; et al. A experimentação na identificação das transformações físicas e químicas. Anais da XIII Jornada de ensino, pesquisa e extensãoJEPEX,2013.Disponívelem:<http://www.eventosufrpe.com.br/2013/cd/resu mos/R1248-1.pdf>. Acesso em: 15 de maio de 2020.

\section{(c) (1) () $९$}


TAHA, Marli Spat; et al. Experimentação como ferramenta pedagógica para o ensino de ciências. Experiências em Ensino de Ciências, V.11, N.1, 2016.

VIEIRA, Maysa Ramos; et al. Mudanças de estados físicos da matéria: fusão, vaporização, condensação, solidificação e sublimação, para deficientes visuais. Anais do Congresso Internacional de Educação e Inclusão, 2014. Disponível em: <http://editorarealize.com.br/revistas/cintedi/trabalhos/Modalidade_1datahora_03 _11_2014_00_21_40_idinscrito_3839_27431d1e21b26b67c008132a424415c3.pdf>. Acesso em: 15 de maio de 2020.

VYGOTSKY, Lev S. A formação social da mente. São Paulo: Martins Fontes, 1994.

ZECHIM, Maria José Cremasco. Caderno pedagógico de atividades práticas e experimentais para uma aprendizagem significativa de conceitos físicos na ciência. Secretaria de estado da educação. Bandeirantes, Paraná. 2008. Disponível em: <http://www.diaadiaeducacao.pr.gov.br/portals/pde/arquivos/1874-6.pdf.> Acesso em: 10 de julho de 2019.

\section{(1) (1) (9)}

